University of Nebraska - Lincoln

DigitalCommons@University of Nebraska - Lincoln

Faculty Publications: Agricultural Economics

Agricultural Economics Department

2-1-2005

Productivity and Welfare

Lilyan E. Fulginiti

University of Nebraska-Lincoln, Ifulginiti1@unl.edu

Richard K. Perrin

University of Nebraska-Lincoln, rperrin@unl.edu

Follow this and additional works at: https://digitalcommons.unl.edu/ageconfacpub

Part of the Agricultural and Resource Economics Commons

Fulginiti, Lilyan E. and Perrin, Richard K., "Productivity and Welfare" (2005). Faculty Publications:

Agricultural Economics. 15.

https://digitalcommons.unl.edu/ageconfacpub/15

This Article is brought to you for free and open access by the Agricultural Economics Department at DigitalCommons@University of Nebraska - Lincoln. It has been accepted for inclusion in Faculty Publications: Agricultural Economics by an authorized administrator of DigitalCommons@University of Nebraska - Lincoln. 


\section{Productivity and Welfare ${ }^{\star}$}

LILYAN E. FULGINITI*

lfulginiti@unl.edu

University of Nebraska, USA

rperrin@unl.edu

RICHARD K. PERRIN

University of Nebraska, USA

\section{Abstract}

Technical change is generally characterized by a rate and biases, both evaluated for given producer prices. This paper examines the potential discrepancy between this rate and the corresponding rate of consumer welfare change as measured by Allais distributable surplus. We postulate a general equilibrium context with various market failures (taxes, quotas, imperfect competition, and "poorly priced" commodities), and use comparative statics to express the rate of welfare change in terms of the rate and biases of the technical change. An elementary simulation model of a taxed economy suggests that the rate of welfare change may differ from the rate of technical change by as much as $50 \%$ under plausible circumstances.

JEL Classifications: D2, D5, D6, O3

Keywords: productivity, Allias surplus, general equilibrium

The very existence of the concept of productivity change, an increase in output per input, is due to its implications for improved human welfare. Despite this human welfare motivation, the productivity literature has tended to focus on the production process itself to measure productivity change. ${ }^{1}$

The limitations of focusing on the production process are evident when one considers that, because of the law of conservation of mass and energy, what goes into the production process must always come out, and therefore in a fundamental sense there can be no productivity change. What production theory identifies as "technology" is the relationship between achievable combinations of selected inputs and outputs - the selection process giving a weight of one to inputs and outputs deemed significant to human welfare, and a weight of zero to others. A zero-one weighting system for welfare relevance is crude, but necessary for the useful process of identifying the technological possibilities with respect to welfaresignificant inputs and outputs. But a change in the production technology does

\footnotetext{
* Contribution of the University of Nebraska Agricultural Experiment Station, Lincoln, NE 68583.

* Corresponding author.
} 
not reveal a change in welfare because of the crudeness of this zero-one weighting system. While it is possible to measure local shifts in the technology with distance functions or supporting hyperplanes, such production-oriented measures of productivity change will measure welfare change only if the implicit weights are the correct welfare weights, which is unlikely for a number of reasons that we specify later.

In this paper, we explicitly relate changes in the technology set to changes in welfare in a general equilibrium context that allows for departures from Pareto optimality. We characterize technology change in terms of the rate and biases of the local shift of the technology set. We characterize the associated welfare change in terms of the Allais-Debreu notion of distributable surplus. We express the resulting Allais index of productivity change in terms of the rate and biases of technical change and parameters representing market imperfections. This analysis allows us to identify the circumstances which cause divergences between the Allais welfare index of productivity change and the more traditional rate of technical change, and to assess the extent of those divergences. Divergences we identify and measure are those due to price distortions from taxes and subsidies, quotas, market power, "poorly-priced" commodities, and those due to price changes induced by the change in technology.

For many empirical purposes, traditional measures such as the rate of technical change or total factor productivity will be adequate approximations of the welfare effects of technical change. We provide some simulation results however, that illustrate that the potential divergence can be as much as fifty percent in the case of heavily taxed or subsidized sectors. In any case, the analysis here helps to clarify the relationships between welfare, productivity and technical change, for as Hicks (1945-1946) wrote with regard to his own study of alternative welfare measures, "... for the purpose of clear thinking it is necessary that the basic measures should be distinguished, and their relationship cleared up."

The paper is organized as follows. In Sections 1 and 2 we present the measures of technical change and welfare change, respectively. In Section 3 we develop the Allais welfare measure of technical change, we place it in the context of a closed-economy general equilibrium and examine the comparative statics effects of technical change. In Section 4 we extend these results to various situations of market failure, and in Section 5 we present an example by simulating divergences between the production-oriented vs welfare-oriented measures.

\section{Measures of Technical Change}

Traditionally, productivity growth is defined as the difference between the growth rates of output produced and input used. ${ }^{2}$ The underlying idea is that this difference reflects a change in technology that allows more output to be produced from a given amount of inputs. The indicators of technical change described in this section infer technological changes from the production behavior of firms, using either econometric methods or index numbers. The idea underlying these measures is that 

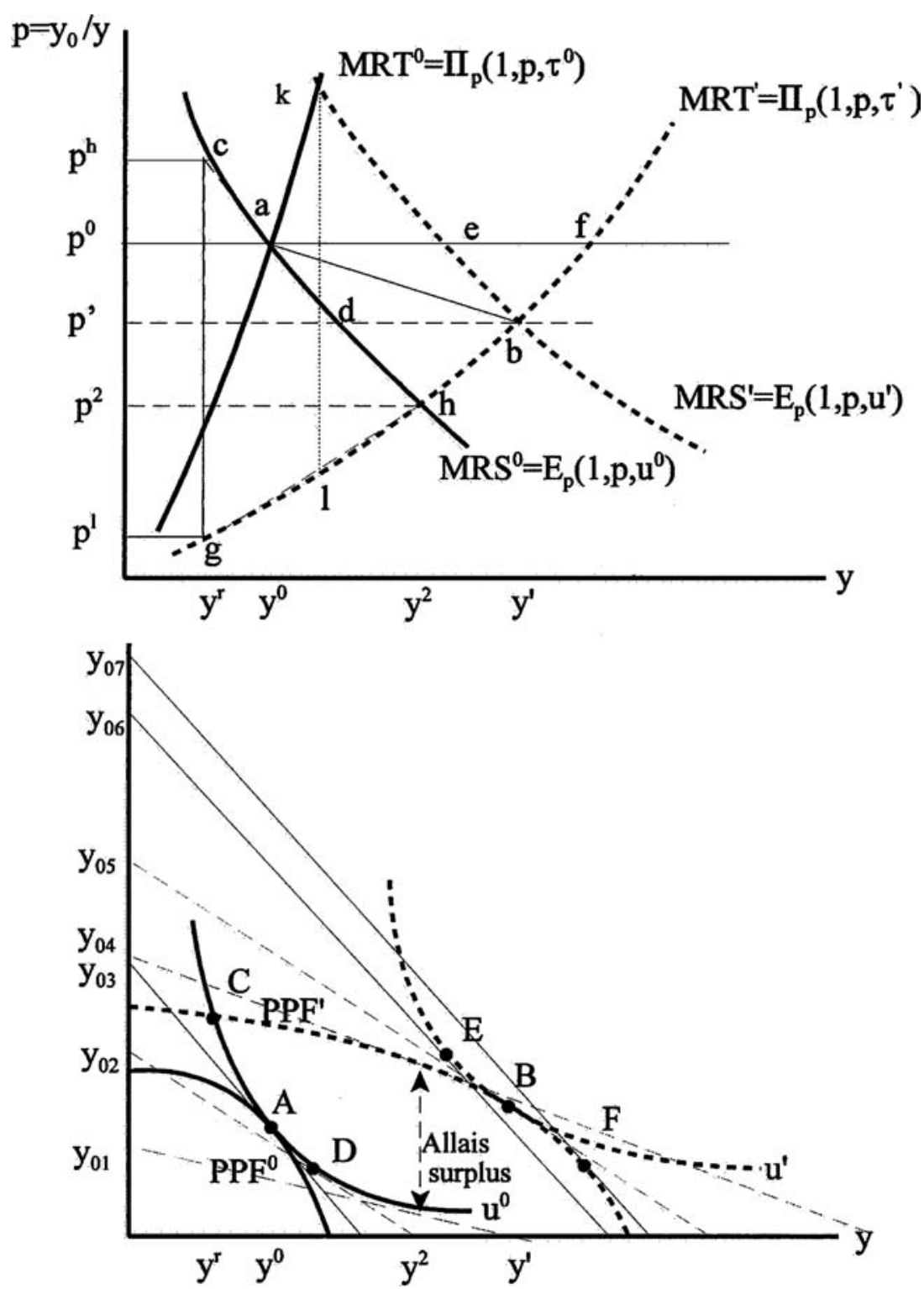

Figure 1. Welfare effects of technological change with no price distortions.

productivity growth has occurred if the cost of production of a given output has declined or if profits increase for given prices. ${ }^{3}$

This literature has focused on scalar measures of the rate of change that characterize such changes as the one from $\mathrm{PPF}^{0}$ to $\mathrm{PPF}^{\prime}$ in Figure 1. In this figure the lower panel shows the numeraire good $y_{0}$ on the vertical axis, the other good $y$ 
on the horizontal axis, an initial technology and initial welfare level represented by $\mathrm{PPF}^{0}$ and $u^{0}$, and a subsequent technology and welfare level represented by $\mathrm{PPF}^{\prime}$ and $u^{\prime}$. In the upper panel the MRS curves (Hicksian demand schedules) are slopes of the respective indifference curves in the lower panel, and the MRT curves (supply schedules) are slopes of the production possibility curves. The initial equilibrium at point $A$ in the lower panel corresponds to point $a$ in the upper panel. In general, no unique scalar value measures "the" increase in productivity, so a number of such scalar measures have been proposed. ${ }^{4}$ The commonly-used measure of the rate of technical change which we adopt here is that of Samuelson, Dixit and Norman, Woodland, Diewert and Morrison, and others. It is the relative change in maximum variable profits for a given set of prices and resources, which we define and use as have Diewert and Morrison and Diewert and Nakamura.

To derive algebraic measures of this concept of technical change, we begin with the aggregate profit function. Given a vector of fixed resources, $z$, the production sector of the economy chooses net output vector $\left(y_{0}, \boldsymbol{y}\right)$ in its feasible production set, $\left(y_{0}, \boldsymbol{y}, \boldsymbol{z}\right) \in T$, so as to maximize profits given the vector of producer prices $(1, \boldsymbol{p})$. It is assumed that the production set $T$ is non-empty, closed and convex. In perfect competition, the aggregate restricted profit function represents the solution to the following problem

$$
\Pi(1, \boldsymbol{p}, \boldsymbol{z}, \boldsymbol{\tau}) \equiv \operatorname{Max}_{y_{0} y}\left[y_{0}+\boldsymbol{p} \boldsymbol{y} \mid\left(y_{0}, \boldsymbol{y}, \boldsymbol{z}, \boldsymbol{\tau}\right) \in T\right]
$$

where $\tau$ is a technology index, $y_{0}$ is a numeraire commodity with a price of unity, $\boldsymbol{y}$ and $\boldsymbol{p}$ are vectors of non-numeraire netputs and their respective prices, $\boldsymbol{z}$ is a vector of fixed resources and the optimal choice of $\boldsymbol{y}$ satisfies $^{5}$

$$
\boldsymbol{y}=\Pi_{p}(1, \boldsymbol{p}, \boldsymbol{z}, \boldsymbol{\tau}) \equiv \nabla_{p} \Pi(1, \boldsymbol{p}, \boldsymbol{z}, \boldsymbol{\tau}) .
$$

Technical change ${ }^{6}$ (TC) evaluated at initial equilibrium prices $\mathbf{p}^{0}$ is ${ }^{7}$

$$
\text { TechnicalChange } e^{0}\left(\mathrm{TC}^{0}\right) \equiv \Pi\left(1, \boldsymbol{p}^{0}, \boldsymbol{z}, \boldsymbol{\tau}^{\prime}\right)-\Pi\left(1, \boldsymbol{p}^{0}, \boldsymbol{z}, \boldsymbol{\tau}^{0}\right) .
$$

In the two-good economy illustrated in Figure $1, \mathrm{TC}^{0}$ corresponds to $\left(y_{07}-y_{03}\right)$ in the lower panel and to the area cafg in the upper panel. ${ }^{8}$ This is Hicks' Producers' Equivalent Variation, reflecting the change in producer surplus as a result of a technical change that shifted the economy from an initial equilibrium, evaluating this change at initial equilibrium prices. This definition and its graphical illustration provide an obvious parallel with the definition of Hicksian variations most commonly used to measure consumer surplus changes. The rate of technical change $(\delta)$ that is used in this paper is the derivative equivalent of this definition, as a fraction of initial profit, or $\delta=(d \Pi / d \tau) / \Pi .^{9}$

The nature of technological change can be characterized by bias as well as rate, as originally suggested by Hicks. Here we use the Binswanger definition (1974) of netput bias as the percentage change in the share of netput in profit due to the technological change under constant prices, $\beta_{i}=d \ln k_{i} / d \tau$, where $k_{i}=p_{i} y_{i} / \Pi$. It is easily shown that share-weighted biases so defined must sum to zero, and that 
they may also be expressed as $\beta_{i}=\nabla_{p i, \tau}^{2} \Pi / y_{i}-\delta$, that is, the difference between the rate of change of netput $y_{i}$ and the rate of change in profit. Thus the technological change can be characterized by the rate $\delta$ plus a vector of $n \times 1$ biases $\beta$ defined as

$$
\text { Bias of Technological Change } \equiv \beta \equiv \frac{d \ln k}{d \tau}=\hat{y}^{-1} \nabla_{p \tau}^{2} \Pi-\imath \delta,
$$

where $\hat{y}$ indicates a matrix with vector $y$ displayed on the diagonal, and $\imath$ is a $n \times 1$ unit vector.

With unbiased technological change under constant prices, every netput changes at the rate of technological change $\delta$, and thus there are no changes in shares. This is equivalent to a homothetic shift in the technology set, which in Figure 1 corresponds to a radial expansion of the $P P F$, rather than the expansion shown, which is biased in favor of output $y$ and therefore biased against output $y_{0}$.

For notational simplicity we henceforth suppress the vector $z$, with the understanding that $\Pi(1, \boldsymbol{p}, \boldsymbol{\tau})$ continues to represent the returns to fixed resources.

\section{Partial Equilibrium Measures of Welfare Change}

One of the earliest concepts for measuring welfare change is the notion of consumer surplus due to Dupuit and Marshall. Their approach defined surplus in the context of supply and demand curves in a market for the commodity subject to taxation. ${ }^{10}$ The Griliches (1957) study of the impact of hybrid corn technology was one of the first to use this approach to empirically measure welfare effects of an innovation. The welfare measure he used was the change in social surplus (consumer and producer surplus) in the market for corn. Many partial equilibrium studies that followed Griliches' examined the distribution of welfare benefits due to process or product innovations. Most of these studies used the Marshallian surplus notion to evaluate the welfare impact of a research-induced supply shift. It is now widely accepted that Marshallian consumer surplus is deficient as a welfare measure.

A more acceptable welfare measure is Hicks' Equivalent Variation (EV). This measure of the welfare effect of a change from state A to state B is the minimum amount of money that if given to consumers in state A, would permit the consumer to achieve the utility level of state B. ${ }^{11}$ This concept is easily represented in terms of expenditure functions. If the choice $\left(y_{0}, \boldsymbol{y}\right)$ of a representative consumer is obtained from minimizing expenditures necessary to attain a particular utility level $u$ given prices $(1, \boldsymbol{p})$, then the following expenditure function represents the solution to that minimization problem:

$$
E(1, p, u) \equiv \operatorname{Min}_{y_{0}, y}\left[y_{0}+\boldsymbol{p} \boldsymbol{y} \mid u\left(y_{0}, \boldsymbol{y}\right) \geq u\right],
$$

where $y_{0}$ is the numeraire commodity with price set to unity and the optimal choice $\boldsymbol{y}$ satisfies $^{12}$

$$
\boldsymbol{y}=E_{p}(1, \boldsymbol{p}, \boldsymbol{u}) \equiv \nabla_{p} E(1, \boldsymbol{p}, \boldsymbol{u}) .
$$


If the technological change moved the economy from an initial equilibrium $\left(1, \boldsymbol{p}^{0}, \boldsymbol{u}^{0}\right)$ to $\left(1, \boldsymbol{p}^{\prime}, \boldsymbol{u}^{\prime}\right)$, then EV is defined as ${ }^{13}$

$$
\text { Equivalent Variation(EV) } \equiv E\left(1, \boldsymbol{p}^{0}, \boldsymbol{u}^{\prime}\right)-E\left(1, \boldsymbol{p}^{0}, \boldsymbol{u}^{0}\right) .
$$

In Figure 1, EV corresponds to $y_{06}-y_{03}$ which is equal to the area caebg in the upper panel.

\section{General Equilibrium Welfare-Theoretic Measure of Productivity}

The partial equilibrium measures of the benefits of innovations presented in earlier sections are conceptually inadequate because they do not address the gains or losses imposed on the remainder of the economy when reallocations are made to particular consumers or in the markets for particular commodities. Also, when there are market failures, a production oriented measure such as TC differs from a consumption oriented measure such as EV. To resolve these discrepancies the conceptual framework must be based on some type of general equilibrium analysis that allows for price endogeneity and for departures from Pareto optimality.

The approach we propose to measuring welfare effects of an innovation has its roots in the work of Pareto, with more recent contributions by Allais $(1973,1977)$ and Debreu (1931), whose work Diewert (1981) refers to as "quantity-oriented" (measuring welfare change in units of goods.) We consider this approach consistent with the spirit of general equilibrium, where prices are not fixed but endogenous. While most of the work using these concepts, mainly by Diewert (1981, 1983), has focused on taxation as the cause of welfare change, we expand it to consider the welfare gain emanating from a profit increasing innovation.

Allais defines his measure of the welfare effect of a distortion, the distributable surplus or Allais surplus (AS), as the maximum amount of a particular good that could be extracted from the distorted economy and discarded, without making any household worse off than in the distorted state, while maintaining the economy in equilibrium. For a given state of the economy, such a surplus is an intuitive measure of the welfare loss inherent in that state relative to a Pareto optimal allocation. The Allais approach here involves comparison of an initial, pre-innovation equilibrium with a hypothetical post-innovation reference equilibrium in which all households are at the same utility level as at the initial equilibrium, but some physical good has been extracted. The reference equilibrium is hypothetical in that the analysis does not presuppose that such a reallocation would actually occur, even though an omniscient government might affect such a reallocation and redistribute the distributable surplus in some way that is irrelevant to the measure itself. Debreu's "coefficient of resource utilization" is based on this concept, but his disposable surplus is measured in terms of the basket of resources rather than any particular good. In the two-goods case of Figure 1, bottom panel, the Allais measure in terms of numeraire surplus appears as the maximum vertical line between $\mathrm{PPF}^{\prime}$ and $u^{0}$. 
Consider now a general equilibrium for a closed economy in which a representative consumer expenditure function and an aggregate profit function possess the usual characteristics and can be represented by

$$
\begin{aligned}
& E(1, \boldsymbol{p}, \boldsymbol{u}) \equiv \operatorname{Min}_{y_{0}, \boldsymbol{y}}\left[y_{0}+\boldsymbol{p} \boldsymbol{y} \mid u\left(y_{0}, \boldsymbol{y}\right) \geq \boldsymbol{u}\right] \quad \text { and } \\
& \Pi(1, \boldsymbol{p}, \boldsymbol{\tau}) \equiv \operatorname{Max}_{y_{0}, \boldsymbol{y}}\left[y_{0}+\boldsymbol{p} \boldsymbol{y} \mid\left(y_{0}, \boldsymbol{y}, \boldsymbol{z}, \boldsymbol{\tau}\right) \in \boldsymbol{T}\right],
\end{aligned}
$$

where: $y_{0}$ is netput quantity of the numeraire good, $y$ is an $n \times 1$ vector of netput quantities of other goods, $p$ is an $n \times 1$ vector of prices for $y, z$ is an $n \times 1$ vector of fixed resources, suppressed hereafter, $u$ is the consumer's utility function, $\tau$ is an index of technological change, $T$ is the feasible technology set.

The general equilibrium conditions for this closed, competitive economy require that consumer expenditures must equal consumer income and that commodity markets must clear. These general equilibrium conditions may be represented by the following equations:

$$
\begin{aligned}
& E(1 \cdot \boldsymbol{p}, \boldsymbol{u})=\Pi(1, \boldsymbol{p}, \boldsymbol{\tau}), \\
& \nabla_{p} E=\nabla_{p} \Pi
\end{aligned}
$$

Subscripts represent partial derivatives, both the producer and consumer price of the numeraire good must equal one, and there are $n$ relative prices and the utility level $u$ to be determined by these $n+1$ equations.

First we wish to consider a "once and for all" exogenous shock to this system in the form of a technological change from $\tau^{0}$ to $\tau^{\prime}$ in a perfectly competitive economy, as is illustrated for the two-good case without distortions in Figure 1. Later we will extend the analysis to incorporate departures from Pareto optimality. Our measure of the welfare effect of this shock to the system is the Allais distributable surplus (AS) defined as the maximum amount of numeraire commodity that could be extracted from the economy with the new technology while keeping consumers at the original utility level and the economy in equilibrium, or

$$
\mathrm{AS}=\Pi\left(1, \boldsymbol{p}, \tau^{\prime}\right)-E\left(1, \boldsymbol{p}, \boldsymbol{u}^{0}\right) \quad \text { such that } \nabla_{p} E\left(1, \boldsymbol{p}, \boldsymbol{u}^{0}\right)=\nabla_{p} \Pi\left(1, \boldsymbol{p}, \tau^{\prime}\right)
$$

where expenditures and profits are measured in numeraire units (good $\left.y_{0}\right)$, and the supply-demand conditions are for all goods but the numeraire. ${ }^{14}$ Note that prices are determined endogenously rather than being fixed at the pre- or post-innovation level. ${ }^{15}$ A casual comparison with Technical Change in equation (3) and EV in equation (7) reveals the difference between a pure production measure, a pure consumption measure, and this general equilibrium measure.

In the two good case of Figure 1, bottom panel, the Allais measure AS appears as the maximum vertical line between $\mathrm{PPF}^{\prime}$ and $u^{0}$, where the slopes of the two curves are equal, or $y_{04}-y_{01}$. In the top panel this measure is equal to the area of the triangle $c h g .{ }^{16}$ The reference point $C$, or $\left(y^{r}, y_{0}^{r}\right)$, is a combination of goods on the frontier of the new technology that would provide exactly the level of welfare as the initial equilibrium. 
To quantify the general equilibrium welfare effects of technological change we modify the equilibrium conditions (9) to include the Allais surplus:

$$
\begin{aligned}
& E(1, \boldsymbol{p}, \boldsymbol{u})+A S=\Pi(1, \boldsymbol{p}, \tau), \\
& \nabla_{p} E=\nabla_{p} \Pi .
\end{aligned}
$$

Note that (11) is an alternative way of writing the definition in (10).

To solve for the Allais surplus created by a technological change $d \tau$, we totally differentiate the equations in (11) and set $d u=0$, i.e., there is to be no change in the utility level:

$$
\begin{aligned}
& \nabla_{p} E \boldsymbol{d} \boldsymbol{p}+\mathrm{dAS}=\nabla_{p} \Pi \boldsymbol{d} \boldsymbol{p}+\nabla_{\tau} \Pi d \tau, \\
& \nabla_{p p}^{2} E \boldsymbol{d} \boldsymbol{p}=\nabla_{p p}^{2} \Pi d p+\nabla_{\tau} \Pi d \tau .
\end{aligned}
$$

Note that because $\nabla_{p} E=\nabla_{p} \Pi, \boldsymbol{d} \boldsymbol{p}$ disappears from (12a), and we can solve (12b) for the price effect of technological change

$$
\boldsymbol{d} \boldsymbol{p}=\left(\nabla_{p p}^{2} \boldsymbol{E}-\nabla_{p p}^{2} \Pi\right)^{-1} \nabla_{p \tau}^{2} \Pi d \tau
$$

which can be expressed in terms of the rate, $\delta$ and biases $\beta$, of the technological change and supply and demand elasticities as

$$
\frac{\boldsymbol{d} \ln \boldsymbol{p}}{d \tau}=(\boldsymbol{H}-\boldsymbol{\Sigma})^{-1}(\iota \delta+\boldsymbol{\beta}),
$$

where $\boldsymbol{d} \ln \boldsymbol{p}$ is a vector of logarithmic price changes, $\boldsymbol{H}$ is a matrix of compensated demand elasticities, $\boldsymbol{\Sigma}$ is a matrix of supply elasticities, and $\boldsymbol{\imath}$ is a $n \times 1$ vector of ones. ${ }^{17}$ Note also from equation (12a) that to a first degree, the Allais welfare change is equal to the rate of technical change.

From equation (14) it is clear that there are two sufficient conditions for the Allais surplus extraction to have no induced price effects. The first condition is that all non-numeraire commodity biases be identical and equal to the negative of rate of technical change $\left(-\delta=\beta_{i}\right)$. This implies that the bias of technical change for the numeraire commodity is $\beta_{0}=\left(1 / k_{0}-1\right) \delta$. The second condition is that all prices be exogenous i.e., when the diagonal elements of the matrices $\boldsymbol{\Sigma}$ or $\boldsymbol{H}$ approach infinity.

Using a Taylor expansion of $\operatorname{AS}\left(1, \boldsymbol{p}^{\prime}, \boldsymbol{\tau}^{\prime}\right)$ from (10) about the equilibrium point $\left(1, \boldsymbol{p}^{0}, \tau^{0}\right)$, we obtain a second-order approximation of the AS associated with a once and for all technological change: ${ }^{18}$

$$
\begin{aligned}
\mathrm{AS} \approx & \left(\nabla_{p} \Pi-\nabla_{p} E\right) d p+\nabla_{\tau} \Pi d \tau \\
& +\frac{1}{2}\left(d p^{\mathrm{T}} d \tau^{\mathrm{T}}\right)\left[\begin{array}{cc}
\nabla_{p p}^{2} \mathrm{E}-\nabla_{p p}^{2} \Pi \nabla_{p \tau}^{2} \Pi \\
\nabla_{p \tau}^{2} \Pi & \nabla_{p p}^{2} \Pi
\end{array}\right]\left(\begin{array}{c}
d p \\
d \tau
\end{array}\right) \\
= & \nabla_{\tau} \Pi d \tau+d p^{\mathrm{T}} \nabla_{p \tau}^{2} \Pi d \tau+\frac{1}{2} d p^{\mathrm{T}}\left(\nabla_{p p}^{2} \Pi-\nabla_{p p}^{2} E\right) d p+\frac{1}{2} d p^{\mathrm{T}}\left(\nabla^{2}{ }_{\tau \tau} \Pi\right) d p \\
= & \nabla_{\tau} \Pi d \tau-\frac{1}{2} \nabla_{p \tau}^{2} \Pi\left(\nabla_{p p}^{2} \Pi-\nabla_{p p}^{2} E\right)^{-1} \nabla_{p \tau}^{2} \Pi d \tau
\end{aligned}
$$


where subscripts indicate differentiation and $\nabla^{2}{ }_{\tau \tau} \Pi=0$. Given that the second term of the last line of equation (15) is positive, then to a second degree approximation, the measure of welfare change is at most as big as the measure of technical change. Dividing AS by initial expenditures $E^{0}=E\left(1, \boldsymbol{p}^{0}, \boldsymbol{u}^{0}\right)$, allows us to express $\mathrm{AS}$ as a fraction of initial expenditures, and (15) in terms of shares and elasticities: ${ }^{19}$

$$
\begin{aligned}
\frac{\boldsymbol{d}}{\boldsymbol{d} \tau} \frac{\mathrm{AS}}{E^{0}} & \approx \delta+(\iota \delta+\beta) \hat{\boldsymbol{s}} \boldsymbol{d} \ln \boldsymbol{p}+(l \delta+\beta)^{\mathrm{T}} \hat{\boldsymbol{s}}(\Sigma-\boldsymbol{H}) \boldsymbol{d} \ln \boldsymbol{p} \\
& \approx \delta-\frac{1}{2}(\iota \delta+\beta)^{\mathrm{T}} \hat{\boldsymbol{s}}(\Sigma-\boldsymbol{H})^{-1}(l \delta+\beta)
\end{aligned}
$$

where $s$ is an $n \times 1$ vector of expenditure shares, $\hat{s}$ is a diagonal matrix, and in the last expression in (16) we have substituted the price change from equation (14).

Equation (16) is a primary analytical result of this paper, an explicit solution of the consumers' potential welfare gains ${ }^{20}$ from technical change in a perfectly competitive economy with no market failures, as a function of the rate and bias characteristics of that technical change. It establishes that to the extent that there are induced price effects, the rate of technical change $\delta$ will most likely overestimate the welfare impact of an innovation.

\section{Welfare-Theoretic Measure of Productivity Under Market Failure}

We now return to the issue of the potential mistakes incurred in productivity measurement when market prices do not reflect the subjective valuation of consumers, due to market failure. ${ }^{21}$ As we mentioned before, the practice of focusing on production effects rather than consumption effects introduces two potential sources of error in the evaluation of the economic impact of technical change. These are the use of the producers' evaluations rather than the consumers' evaluations of these impacts, and the omission of induced price effects due to technical change. It is clear from the last section that omission of induced price effects is a cause of error even in perfect markets when a general equilibrium welfare measure, like $\mathrm{AS} / E$, is used. We now show how this measure differs from the rate of technical change in the presence of departures from Pareto optimality due to (a) ad valorem taxes and subsidies; (b) production quotas and rationing; (c) imperfect competition in the final commodity market; (d) imperfect competition in the intermediate commodity market; and (e) "poorly priced" commodities. ${ }^{22}$ In doing so we will establish the conditions under which there is no discrepancy between the rate of technical change, $\delta$, and $\mathrm{AS} / E$ in the presence of market failure. We will show that this is so only in very unusual circumstances.

\subsection{Ad Valorem Taxes and Subsidies}

We modify the general equilibrium conditions in equation (9) to describe a general equilibrium in the presence of ad valorem taxes $(\rho>0)$ or subsidies $(\rho<0)$, 
so that prices that consumers pay, $\boldsymbol{p}$, are no longer equal to prices that producers receive, $w$ :

$$
\begin{aligned}
& E(l, \boldsymbol{p}, \boldsymbol{u})+\mathrm{AS}=\Pi(l, \boldsymbol{w}, \boldsymbol{\tau})+\rho \hat{\boldsymbol{w}} \nabla_{\boldsymbol{w}} \Pi \\
& \nabla_{\boldsymbol{p}} E=\nabla_{\boldsymbol{w}} \Pi \\
& \boldsymbol{p}=(\boldsymbol{I}+\hat{\boldsymbol{\rho}}) \boldsymbol{w},
\end{aligned}
$$

where: $\rho$ is a vector of wedges between consumer and producer prices, $\hat{\rho}$ indicates a matrix with vector $\rho$ on the diagonal, and $\hat{\boldsymbol{w}}$ indicates a matrix with vector $\boldsymbol{w}$ on the diagonal.

We examine the comparative statics of this $1+2 n$ equation equilibrium system by taking log-differentials of the equations in (17), as we did in deriving equations (15) and (16), noting that (17c) implies $(\boldsymbol{d} \ln \boldsymbol{p}=\boldsymbol{d} \ln \boldsymbol{w})$. We solve this system for the induced price change which in this case is the same as equations (14) and (15). Using a Taylor expansion of $\operatorname{AS}\left(1, \boldsymbol{p}^{\prime}, \boldsymbol{w}^{\prime}, \boldsymbol{\tau}^{\prime}\right)$ about the equilibrium point $\left(1, \boldsymbol{p}^{0}, \boldsymbol{w}^{0}, \tau^{0}\right)$, we obtain a second-order approximation of the AS associated with technological change in the presence of price distortions. We ignore third and higher-over derivatives of expenditure and profit functions, effectively assuming them to be zero. This means we are dealing with linear demand and supply responses in the vicinity of the initial equilibrium. ${ }^{23}$ Expressed in terms of shares and elasticities, AS as a fraction of initial expenditures is

$$
\begin{aligned}
\frac{\boldsymbol{d}}{\boldsymbol{d} \tau} \frac{\mathrm{AS}}{\mathrm{E}_{0}} \approx & \delta\left(1-\frac{1}{1+\rho \mathbf{k}} \rho \hat{\mathbf{k}} \Sigma(\Sigma-H)^{-1} \iota\right)-\frac{1}{1+\rho \mathbf{k}} \rho \hat{\mathbf{k}} H(\Sigma-H)^{-1} \beta \\
& -\frac{1}{2+2 \rho \mathbf{k}}(\iota \delta+\beta)^{\mathrm{T}}\left[\hat{\mathbf{k}}-(\Sigma-H)^{-1 \mathrm{~T}} \hat{\rho} \hat{\mathbf{k}} H\right](\Sigma-H)^{-1}(\iota \delta+\beta),
\end{aligned}
$$

where $\mathbf{k}$ is an $n \times 1$ vector of profit shares. Compared to equation (16) we note that policy distortions cause a first order departure of the rate of welfare from the rate of technical change, while induced price changes remain to contribute slightlyaltered second order departures. It is clear that the rate of technical change $\delta$ differs from the welfare measure AS/E due to first order policy distortions $(\rho \neq 0)$ and second order induced price changes. We will pursue the analysis of this case in more detail below.

\subsection{Quotas and Rationing}

We modify equation (9) to describe a general equilibrium in the presence of production quotas or rationing. In this case the netput vector $y$ is composed of two sub-vectors, an $n \times 1$ vector of unconstrained netputs, $y_{1}$, and an $m \times 1$ vector of netputs with quantity determined by quotas or rationing, $y_{2}$, i.e., $y=\left(y_{1}, y_{2}\right)$. Consequently the price vector, $p$ for consumer prices and $w$ for producer prices, will also be partitioned. In addition to the sub-vector of prices for the unconstrained commodities, $p_{1}$ for both producers and consumers, we include virtual prices for constrained commodities. Producers' virtual price sub-vector $w$ consists of those 
prices that would induce production of the quota quantities $y_{2}$, so that prices relevant to producers are $\left(p_{1}, w\right)$. Similarly, consumers' virtual price vector $v$ consists of those prices that induce consumers to demand exactly the ration $y_{2}$, and prices relevant to consumers are $\left(p_{1}, v\right)$. The quota-constrained general equilibrium conditions can be now expressed as

$$
\begin{aligned}
& E\left(1, p_{1}, v, u\right)+\mathrm{AS}=\Pi\left(1, p_{1}, w, \tau\right)+(v-w) y_{2} \\
& \nabla_{p_{1}} E=\nabla_{p_{1}} \Pi \\
& \nabla_{v} E=y_{2} \\
& \nabla_{w} \Pi=y_{2} .
\end{aligned}
$$

This system has $1+n+2 m$ equations. We solve it for the corresponding price changes which look similar to those in equation (14)

$$
\frac{\mathrm{d} \ln \tilde{p}}{d \tau}=(\tilde{H}-\tilde{\Sigma})^{-1}(\tilde{i} \delta+\tilde{\beta})
$$

but with the elements redefined as follows:

$$
\begin{gathered}
\widetilde{H}=\left[\begin{array}{lll}
H_{1 p} & H_{1 v} & 0 \\
H_{2 p} & H_{2 v} & 0 \\
0 & 0 & 0
\end{array}\right], \quad \widetilde{\Sigma}=\left[\begin{array}{lll}
\Sigma_{1 p} & 0 & \Sigma_{1 w} \\
0 & 0 & 0 \\
\Sigma_{2 p} & 0 & \Sigma_{2 w}
\end{array}\right], \quad \widetilde{i}=\left[\begin{array}{lll}
i_{m} & 0 & i_{n}
\end{array}\right]^{\mathrm{T}}, \\
\widetilde{\beta}=\left[\begin{array}{lll}
\beta_{1} & 0 & \beta_{2}
\end{array}\right]^{\mathrm{T}}, \quad \tilde{p}=\left[\begin{array}{lll}
p & v & w
\end{array}\right]
\end{gathered}
$$

where subscripts 1 and 2 refer to unconstrained and constrained commodities respectively, $\Sigma_{1 p}$ and $\Sigma_{2 p}$ are price elasticities of supply of $y_{1}$ and $y_{2}$ with respect to market and virtual price vectors, respectively, and similarly for $H_{1 p}$ and $H_{2 p}$. The second order Taylor approximation of the AS/E associated with technological change in the presence of rationing and quotas can be derived as before, yielding

$$
\begin{aligned}
\frac{d \mathrm{AS}}{d \tau E_{0}} \approx & \left(s_{1} i\right) \delta+s_{1} \beta_{1}-\hat{s}_{1} \Sigma_{1 w} \Sigma_{2 w}{ }^{-1}\left(i_{n} \delta+\beta_{2}\right) \\
& -\frac{1}{2}(\tilde{i} \delta+\tilde{\beta})^{\mathrm{T}} \hat{s}(\tilde{\Sigma}-\tilde{H})^{-1}(\tilde{i} \delta+\tilde{\beta})
\end{aligned}
$$

where $s_{1}$ is the vector of shares of $y_{1}$ in consumer expenditures, $k_{1}$ the vector of shares in producer profits. Equation (22) shows that in the presence of quotas or rationing, the welfare effect $\mathrm{AS} / E$ is less than the rate of technical change $\delta$ because of inflexibility with respect to the quota good (the vector $s_{2}$ is missing from the first three terms), as well as because of second order price effects (quadratic term.) Note that the first three terms are scaled down in proportion to the combined shares of the unconstrained commodities.

\subsection{Imperfect Competition in the Market for Final Commodities}

There have been a few studies ${ }^{24}$ that modify the calculation of the rate of technical change to account for the presence of markups characteristic of imperfect 
competition, whereas most commonly, productivity studies assume perfectly competitive markets. Innovations are generally protected by Intellectual Property Rights (IPRs) which confer monopoly rights to the innovator so it is logical to allow for them in evaluating welfare benefits of innovations.

Here we modify equation (9) to account for a lack of competitive price conditions in the final product market. The output vector is composed of an $n \times 1$ subvector $y_{1}$ of commodities exchanged in non-competitive markets at price $p_{1}$ and an $m \times 1$ sub-vector $y_{2}$ of commodities exchanged in competitive markets at price $p_{2}$ with a markup of $\rho_{2}$ over marginal cost $v$. This equilibrium is represented by a system of general equilibrium equations similar to equation $(9)^{25}$

$$
\begin{aligned}
& E(1, p, u)+\mathrm{AS}=\Pi(1, w, \tau)+\rho \hat{w} \nabla_{w} \Pi \\
& \nabla_{p} E=\nabla_{w} \Pi \\
& p=(I+\hat{\rho}) w,
\end{aligned}
$$

where: $\boldsymbol{\rho}=\left(0, \rho_{2}\right)$, where $\rho_{2}$ is an $\mathrm{m} \times 1$ vector of markups between consumer prices and producer marginal costs, $\hat{\boldsymbol{\rho}}$ indicates a matrix with vector $\rho$ on the diagonal, $\hat{\boldsymbol{w}}$ indicates a matrix with vector $w$ on the diagonal, $\boldsymbol{p}=\left(\boldsymbol{p}_{1}, \boldsymbol{p}_{2}\right)$, and $\boldsymbol{w}=\left(\boldsymbol{p}_{1}, \boldsymbol{v}\right)$.

Under the non-competitive structure assumed here, we see that the welfare impact of an innovation in a monopolistic market has exactly the same structure and solutions as for the case of a tax equal to the markup. Here, monopoly rents are returned to consumers as owners of the monopolies, whereas earlier, tax returns were returned to consumers for expenditure through their government agent. This means that as we learned before, the rate of technical change will differ from the welfare impact of an innovation depending on the size of the markups and an induced price effect. The size of the markup could be arbitrary, but might also be determined as the set of multi-market Lerner mark-ups, i.e., $\rho_{i}=\left\|-\frac{h_{22}^{i}}{1+h_{22}^{i}}\right\|$ where $\boldsymbol{h}_{22}^{i}$ is the $i$ th row of the inverse matrix of Hicksian demand elasticities for the non-competitive goods $\boldsymbol{y}_{\mathbf{2}}$.

\subsection{Imperfect Competition in the Market for Intermediate Commodities}

We treat this case separately given the prevalence of innovations in intermediate (or input) markets that are protected by IPR's, conferring monopoly rights to the innovator. In the literature, the estimation of productivity is most commonly done in the market for final commodities assuming optimal conditions in the rest of the economy. When monopolistic behavior is present in the intermediate market, the measurement of welfare from the innovation will be affected. Proceeding to measure technical change in the final market will miss this effect and will give a misleading estimate of the impact of the innovation. To adapt the present line of analysis to consider this case, we partition the goods vector into final and intermediate goods. Final goods $y^{f}$ are exchanged in perfectly competitive markets at prices $p^{f}$, with production technology represented by $\Pi^{f}\left(p^{f}, p^{i}, \tau\right)$. 
Intermediate goods $y^{i}$ are exchanged at mark-up prices $p^{i}$ and produced with technology represented by $\Pi^{i}\left(p^{f}, v, \tau\right)$, where $v$ represents marginal cost of producing $y^{i}$. In other words, $v$ is the virtual price that would have induced production $y^{i}=$ $\nabla_{v} \Pi^{i}\left(p^{f}, v, \tau\right)$ under perfectly competitive conditions. The mark-up in this market is $p^{i}=(I+\hat{\rho}) v$, which again might be determined according to the multi-commodity Lerner mark-up described previously, though that is not required in the present analysis. Total intermediate market profits thus equals $\Pi^{i}\left(p^{f}, v, \tau\right)+v^{T} \hat{\rho} y^{i}$. Extending the equilibrium in (9) to represent this situation, we have

$$
\begin{aligned}
& E\left(1, p^{f}, u\right)+\mathrm{AS}=\Pi^{f}\left(1, p^{f}, p^{i}, \tau\right)+\Pi^{i}\left(1, p^{f}, v, \tau\right)+\rho \hat{v} \nabla_{v} \Pi^{i} \\
& \nabla_{p^{f}} E=\nabla_{p^{f}} \Pi^{f}+\nabla_{p^{f}} \Pi^{i} \\
& 0=\nabla_{p^{i}} \Pi^{f}+\nabla_{v} \Pi^{i} \\
& p^{i}=(I+\hat{\rho} v),
\end{aligned}
$$

where: $\rho=\left(p^{i}-v\right)$ is a vector of intermediate goods markups, $\hat{\rho}$ indicates a matrix with vector $\rho$ on the diagonal, $\hat{v}$ indicates a matrix with vector $v$ on the diagonal.

Once again we can describe the Allais price change associated with technical change in a format similar to equation (14), specifically,

$$
\frac{d \ln \bar{p}}{d \tau}=(\bar{H}-\bar{\Sigma})^{-1}(\bar{\delta}+\bar{\beta}),
$$

where now

$$
\begin{aligned}
& \bar{p}=\left(p^{f}, p^{i}\right), \\
& \bar{H}=\left[\begin{array}{ll}
H & 0 \\
0 & 0
\end{array}\right], \quad \bar{\Sigma}=\mathrm{K}^{f} \Sigma^{f}+\mathrm{K}^{i} \Sigma^{i}, \quad \mathrm{~K}^{f}=\left[\begin{array}{rr}
\hat{k}^{f} & 0 \\
0 & I
\end{array}\right], \quad \mathrm{K}^{i}=\left[\begin{array}{cc}
\hat{k}^{i} & 0 \\
0 & I
\end{array}\right], \\
& \bar{\delta}=k^{f} i \delta^{f}+k^{i} i \delta^{i}, \quad \text { and } \quad \bar{\beta}=\mathrm{K}^{f} \beta^{f}+\mathrm{K}^{i} \beta^{i} .
\end{aligned}
$$

Both the rate and bias of overall technical change are weighted averages of their sub-sector counterparts. The second order approximation of AS as a fraction of initial expenditures can then be expressed for the case of monopoly power in intermediate goods as

$$
\begin{aligned}
\frac{1}{E_{0}} \frac{d \mathrm{AS}}{d \tau} \approx & \bar{\delta}+i^{T} \hat{s} \xi(I+\xi)^{-1}\left[I-\Sigma^{i}(\bar{\Sigma}-\bar{H})^{-1}\right](\bar{\delta}+\bar{\beta}) \\
& -\frac{1}{2}(\bar{\delta}+\bar{\beta})^{\mathrm{T}}(\bar{\Sigma}-\bar{H})^{-1 \mathrm{~T}} \hat{s}\left[\bar{\Sigma}+\mathrm{K}^{i} \Sigma^{i} \xi\right](\bar{\Sigma}-\bar{H})^{-1}(\bar{\delta}+\bar{\beta}),
\end{aligned}
$$

where $\xi \equiv\left[\begin{array}{ll}0 & 0 \\ 0 & \hat{\rho}\end{array}\right]$.

Here we see that the first-order welfare effect consists of a share-weighted average of the rates of technical change in the two sectors plus a market power effect due to distortion in the intermediate goods market. While one might expect the market power component to be negative, this is not necessarily the case in this situation where market power exists both before and after the innovation occurs. 


\subsection{Poorly-priced Goods}

The final case of market imperfection we consider includes a vector of goods, $\mathrm{y}_{2}$, such as environmental goods (or bads) for which consumers do not choose the level $y_{2}$, but receive the benefit or disutility gratis, whereas producers choose the quantities supplied by equating marginal cost with some exogenous reservation price not paid in money, $\boldsymbol{w}$ (that could be zero). This general equilibrium can be represented using restricted expenditure and profit functions as

$$
\begin{aligned}
& E\left(1, p_{1}, y_{2}, u\right)+\mathrm{AS}=\Pi\left(1, p_{1}, y_{2}, \tau\right) \\
& \nabla_{p_{1}} E=\nabla_{p 1} \Pi \\
& w=\nabla_{y_{2}} \Pi
\end{aligned}
$$

The total differentials of the second two equations determine the adjustments in price $\boldsymbol{p}_{1}$ and quantity $\boldsymbol{y}_{2}$, rather than just an adjustment in prices as in the other general equilibria previously considered. We represent these variables as $\boldsymbol{q}=$ $\left(\boldsymbol{p}_{1}, \boldsymbol{y}_{2}\right)^{T}$, and the change in equilibrium values is

$$
\frac{d \ln \boldsymbol{q}}{d \tau}=-(\Sigma-\tilde{\mathrm{H}})^{-1} \Omega(\iota \delta+\beta),
$$

where:

$$
\begin{aligned}
& \tilde{H} \equiv\left[\begin{array}{cc}
H_{1_{p_{1}}} & H_{1 v} \\
0 & 0
\end{array}\right], \\
& \Omega \equiv\left[\begin{array}{cc}
I-\Sigma_{1 w} \Sigma_{2 w}^{-1} \\
0 & -\Sigma_{22}^{-1}
\end{array}\right],
\end{aligned}
$$

where subscripts represent matrix partitions and $v=\nabla_{y 2} E$, (the consumers' virtual price.) The second-order approximation of the Allais welfare impact of the technical change is in this case

$$
\begin{aligned}
\frac{1}{E_{0}} \frac{d \mathrm{AS}}{d \tau} \approx \delta & -\left(s_{y}^{\mathrm{T}} \sigma_{12} \sigma_{22}^{-1} \iota\right) \delta+\left[S_{y}-\left(S_{v}-S_{w}\right)(\Sigma-\tilde{\mathrm{H}})^{-1}\right] \Omega \beta \\
- & \frac{1}{2}(\iota \delta+\beta)^{\mathrm{T}} \Omega^{\mathrm{T}}(\Sigma-\tilde{\mathrm{H}})^{-1 T}\left[\hat{S}_{w} \Sigma+\hat{S}_{v} \tilde{\mathrm{H}}-2 \hat{S}_{w} \tilde{H}\right] \\
& \times(\Sigma-\tilde{\mathrm{H}})^{-1} \Omega(\iota \delta+\beta) .
\end{aligned}
$$

where

$$
s_{y} \equiv y_{1} \hat{p}_{1} / E_{0}, S_{y} \equiv\left(s_{y}, 0\right), \quad S_{v} \equiv\left(s_{y}, y_{2} \hat{v} / E_{0}\right), \quad S_{w} \equiv\left(s_{w}, y_{2} \hat{w} / E_{0}\right), \quad v \equiv E_{y_{2}} .
$$

The notation in this case becomes more elaborate due to the asymmetry in producer and consumer responses with respect to the poorly-priced good, but the general structure of results for the case of technical change with poorly-priced goods is similar to other cases examined. The second term adjusts welfare gains downward to account for the assumption in this model that producers do not receive 
compensation for the poorly-priced good. The third term is a bias adjustment similar to those of previous cases. The algebraic structure of the quadratic term can be seen to be an augmented version of the previous cases, and though it is too complicated for qualitative analysis, it is amenable to numerical calculation.

\section{An Illustration: Ad-valorem Taxes and Subsidies}

The discrepancy at issue in this paper is that between the rate of technical change and the Allais welfare measure of the impact of that technical change. We now use the above results for the tax/subsidy case, equation (18), to evaluate the plausible size of this discrepancy. It is useful to express (18) in terms of the induced price changes, as

$$
\begin{aligned}
\frac{d}{d \tau} \frac{\mathrm{AS}}{E}= & \delta+\frac{1}{1+\rho k} \rho \hat{k} \beta+\frac{1}{1+\rho k}\left[\rho \hat{k} \Sigma+(\iota \delta+\beta)^{\mathrm{T}}(I+\hat{\rho}) \hat{k}\right] d \ln p \\
& +\frac{1}{2} \frac{1}{1+\rho k} d \ln p^{\mathrm{T}}[(I-\hat{\rho}) \hat{k}(\Sigma-H)+\hat{\rho} \hat{k} \Sigma] d \ln p .
\end{aligned}
$$

The discrepancy between the welfare effect and the rate of technical change consists of the last three terms of (18a). It is evident that these terms do not go to zero if only the distortions go to zero or only the induced price changes go to zero. Either distortions or price effects are sufficient to cause a discrepancy.

The special case of (18a) for an undistorted economy, i.e. $\rho=0$, is

$$
\frac{\mathrm{AS}}{E}=\delta-\frac{1}{2}(\iota \delta+\beta)^{T}(\Sigma-H)^{-1 T} \hat{k}(\iota \delta+\beta)
$$

which gives us back equation (16). Note that as long as the price effects remain, i. $e$., $\boldsymbol{d} \ln p \neq 0$, there will be a discrepancy between the rate of technical change $\delta$, and $\mathrm{AS} / E$. In general, in an undistorted economy, $\mathrm{AS} / E \leq \delta$ due to the induced price effect of that change captured by the second term in equation (18b), which is always negative. We also see here that in this case the effects of biases on $\mathrm{AS} / E$ are of a second order magnitude (through $d \ln p$ ) and will be small.

Another. special case of (18a) of interest is that of no induced price effects, i.e. $d \ln p=0$ but with policy interventions remaining, i.e. $\rho \neq 0$ :

$$
\frac{\mathrm{AS}}{E}=\delta+\frac{1}{1+\rho k} \rho \hat{k} \beta .
$$

This is consistent with the widely used small open economy models with all prices exogenous because all commodities are tradables. From the second term in (18c), we observe that the rates of welfare change and technical change are not equal for this open economy due to distortions. Furthermore, if the only distortion is a tax levied on a commodity toward which the technical change is biased, the tax itself may cause the welfare effect to be greater than the rate of technical change, or $\mathrm{AS} / E>\delta$. 
Table 1. Allais welfare as a fraction of $\delta$, the rate of technical change. ${ }^{\text {a }}$

\begin{tabular}{llllllll}
\hline & \multicolumn{7}{c}{ Price Wedge in Market $A\left(\rho_{A}\right)$} \\
\cline { 2 - 8 } Bias toward $A\left(\beta_{A}\right)$ & -1 & -0.5 & -0.1 & 0 & 0.1 & 0.5 & 1 \\
\hline-0.5 & 1.52 & 1.17 & 0.94 & 0.89 & 0.84 & 0.65 & 0.45 \\
-0.1 & 1.24 & 1.10 & 1.01 & 0.99 & 0.97 & 0.90 & 0.83 \\
0 & 1.16 & 1.06 & 1.00 & 0.99 & 0.97 & 0.93 & 0.87 \\
0.1 & 1.06 & 1.01 & 0.98 & 0.97 & 0.96 & 0.93 & 0.90 \\
0.5 & 0.62 & 0.70 & 0.74 & 0.75 & 0.76 & 0.79 & 0.82 \\
\hline
\end{tabular}

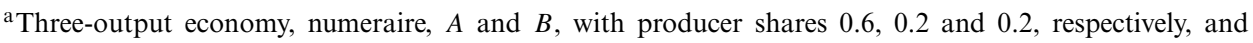
a technical change of rate 0.1 . Supply elasticity matrix is a diagonal of 1 's, demand elasticity matrix a diagonal of -0.5 's. No distortion in market $B$, and no technical change bias for market $B$.

It is evident from (18a) that the rate of technical change, $\delta$, will equal the Allais rate of welfare gain under two circumstances. First, if the economy is not distorted $(\rho=0)$ and if all prices are exogenous $(\boldsymbol{d} \ln p=0) .{ }^{26}$ Second, if a fortuitous combination of parameter values eliminates all but the first term on the right hand side of equations (18a), leaving only $\delta$. This conclusion demonstrates algebraically that the rate of technical change will be an unbiased measure of the welfare effect of technological change only under very unrealistic situations. ${ }^{27}$

Analytical generalizations about when $\mathrm{AS} / E$ is smaller than or bigger than $\delta$ are not tractable in the case of multiple commodities, even though we have noted some regularities about this relationship in the previous section. One regularity is that for an undistorted economy, equation (18b), AS/E is at most equal to $\delta$. Here, the discrepancy between $\mathrm{AS} / E$ and $\delta$ results from the fact that $\delta$ is by definition a fixed priced measure while AS/E accounts for endogenous price changes. The result in (18b) comes as no surprise as it is clear from the index number literature that fixed weight productivity and welfare indexes depart from changing weights indexes of the Törnqvist-Theil type.

It is therefore of interest to use simulation to explore the potential discrepancy between $\delta$ and $\mathrm{AS} / E$. We simulate an economy with three goods, $A, B$, and the numeraire, with the numeraire accounting for $60 \%$ of consumer expenditures and $A$ and $B$ accounting for 20 percent each. ${ }^{28}$ We will examine various levels of distortions in the market for $A$, and various biases toward that commodity.

The results in Table 1 provide a sense of the potential discrepancy between the welfare impact of technical change, and the rate of technical change. Here we have simulated the results of a technical change of rate $\delta=0.10$ and technical change biases toward commodity $A$ (first column) ranging from -0.5 to +0.5 . Note that $\beta_{A}=0$ implies no bias for any commodity. The columns of Table 1 indicate different levels of intervention in market $A$, from a $100 \%$ subsidy to a $100 \%$ tax of that commodity. The market for commodity $B$ is not distorted and technical change is neutral for this commodity.

At the center of the table we see that with no distortions and no bias the second-order induced price effect of equation (18b) reduces the welfare effect by 
only $1 \%$ from the rate of technical change. This numerically confirms the analytical result for an undistorted economy in which we expect $\mathrm{AS} \leq \delta$. We can see further that in extreme cases, the welfare effect may be as much as $52 \%$ larger than the rate of technical change (upper left corner) to as much as 55\% smaller than that rate (upper right corner.) These two extreme cases occur when commodity $A$ receives a $100 \%$ subsidy or a $100 \%$ tax $\left(\rho_{A}=1\right.$ implies that demand price is $100 \%$ greater than supply price), when technology is biased against commodity $A$.

In general, we see from this table that welfare measures of technical change exceed the rate of technical change when that technical change is biased against a commodity that is subsidized. The worst welfare impacts, relative to the rate of technical change, occur when the bias and tax for a commodity have the opposite sign, i.e., when technology is biased against a taxed commodity or toward a subsidized commodity. An example of the latter might be agriculture, which is subsidized in most industrial countries, and toward which technical change is probably biased. A $10 \%$ subsidy and 0.1 bias would reduce welfare gains below the rate of technical change by only $2 \%$, whereas a $10 \%$ subsidy combined with a 0.5 bias, (a rightward agricultural supply shift of $10 \%$ due to $\rho_{A}$ plus $50 \%$ due to $\beta_{A}$ ) would reduce the welfare benefit of technical change by $26 \%$, relative to the rate of technical change of $10 \%$.

While the simulation results demonstrate that the rate of technical change could be a very poor measure of the welfare benefits from technical change, they also suggest that the discrepancy may be only on the order of $5 \%$ or less with small price wedges and biases of -0.1 to +0.1 .

The pattern of results in Table 1 proved to be robust to critical parameter changes. Additional simulations were performed with different supply elasticities, demand elasticities, and shares for commodities $A, B$, and the numeraire. In general, the patterns found in the base simulation of Table 1 survive these parameter changes for commodities $A$ and $B$. We found that as the demand elasticities for $A$ and $B$ decrease and the share of $A$ increases, $\mathrm{AS} / E$ is more sensitive to biases and to policy interventions.

\section{Conclusions}

This paper introduces a general equilibrium measure of welfare gains from technical change, a version of the Allais distributable surplus, and argues for its superiority over the traditionally used rate of technical change. This superiority is derived from the ability of the Allais measure to capture consumers' as well as producers' subjective evaluations and to incorporate "market failures." We use a general equilibrium model to derive and express the Allais rate of welfare gain in terms of the rate and biases of the technical change. The algebraic structure of the solution provides a simple method of computing the price and welfare effects of technical change in general equilibrium.

The main analytical conclusion derived from the analysis is that the rate of technological change, as usually measured from the production perspective, will hardly 
ever be an unbiased measure of the welfare benefits of technical change. The discrepancy arises because technical change may induce price changes, in which case the rate will likely overestimate the welfare benefits, or because of market failures present in the economy.

The analysis is clearly and concisely presented for five different types of "market failures"; (a) ad valorem taxes and subsidies, (b) quotas and rationing, (c) imperfect competition in the final goods market, (d) imperfect competition in the intermediate goods market, and (e) poorly-priced commodities. In each of these cases we set up the general equilibrium equations, derive algebraic representations, and show how to correct for the discrepancy between the rate of technical change and its welfare impact. The welfare measure is summarized in a single comparative statics equation for each case, which for the first time defines the Allais welfaretheoretic measure of the effects of technical change, and expresses it in terms of traditional producer measures, namely the rate of technical change $\delta$ and its vector of biases, $\beta$.

We illustrate this measure for a simulated three-commodity economy with policy distortions, where we find that the discrepancy between the rate of technical change and the rate of welfare change may be as much as $50 \%$ under plausible conditions.

\section{Acknowledgment}

We wish to thank an anonymous reviewer for the depth and quality of the review that was offered.

\section{Notes}

1. Productivity change and technical change are used as synonymous throughout this paper.

2. Since the work of Tinbergen (1942), Solow (1957) and Jorgenson and Griliches (1967) it has become traditional to measure productivity growth as the residual output growth not accounted for by the growth of inputs. This procedure, generally known as the measurement of the "Solow residual," is based on the use of a standard neoclassical production function and the assumptions of perfect competition and constant returns to scale. It involves breaking down the growth rate of aggregate output produced into contributions from the growth of inputs and the growth of technology. Work prior to Solow's is summarized in Griliches (1994).

3. A summary of contributions in this area can be found in Morrison Paul (1999). In particular, Samuelson, Dixit and Norman, Woodland, Diewert, Diewert and Morrison, and Kohli have used a restricted profit function to investigate technical change.

4. See Morrison Paul (1999) for alternative measures used in primal and dual space.

5. Moreover, the profit function $\Pi(1, p, z, \tau)$ is linearly homogeneous and convex in $(1, p)$. If $\Pi(1, p, z, \tau)$ is twice continuously differentiable in $p$ then these properties imply that $\nabla_{p p}^{2} \Pi(1, p, z, \tau)$ is a positive semi-definite matrix such that $p^{T} \nabla_{p p}^{2} \Pi p+2 \nabla_{p 0}^{2} \Pi p+\nabla_{00}^{2} \Pi=0$.

6. In general, technical change can be represented as a difference in levels or as a ratio of levels. If the technological change moved the economy from an initial equilibrium $\left(1, p^{\mathbf{0}}, z, \tau^{\mathbf{0}}\right)$ to $\left(1, \boldsymbol{p}^{\prime}, z, \boldsymbol{\tau}^{\prime}\right)$ then the amount of technical change can be expressed in levels as a change in producer surplus 
evaluated at initial or ex-post prices:

$$
\begin{aligned}
& \text { Technical Change }{ }^{0}\left(\mathrm{TC}^{0}\right) \equiv \Pi\left(\mathbf{1}, \boldsymbol{p}^{\mathbf{0}}, \boldsymbol{z}, \boldsymbol{\tau}^{\prime}\right)-\Pi\left(\mathbf{1}, \boldsymbol{p}^{\mathbf{0}}, \boldsymbol{z}, \boldsymbol{\tau}^{\mathbf{0}}\right), \\
& \text { Technical Change }\left(\mathrm{TC}^{\prime}\right) \equiv \Pi\left(\mathbf{1}, \boldsymbol{p}^{\prime}, \boldsymbol{z}, \boldsymbol{\tau}^{\prime}\right)-\Pi\left(\mathbf{1}, \boldsymbol{p}^{\prime}, \boldsymbol{z}, \boldsymbol{\tau}^{\mathbf{0}}\right) .
\end{aligned}
$$

In terms of Figure $1, \mathrm{TC}^{0}$, evaluated at initial prices, is equivalent to $\left(y_{07}-y_{03}\right)$, or area $g c a f\left(\mathrm{TC}^{\prime}\right.$ is equal to area $g c d b$ ). We note that Hicks did refer to (E1) as producers' Equivalent and Compensating Variations. The relationship between producers' surplus and index number theory has been noticed for some time (Diewert, 1980), and leads to the corresponding technical change indexes:

$$
\begin{aligned}
& Q T C^{0} \equiv \Pi\left(\mathbf{1}, p^{\mathbf{0}}, z, \boldsymbol{\tau}^{\prime}\right) / \Pi\left(\mathbf{1}, \boldsymbol{p}^{\mathbf{0}}, z, \boldsymbol{\tau}^{\mathbf{0}}\right), \\
& Q T C^{\prime} \equiv \Pi\left(\mathbf{1}, \boldsymbol{p}^{\prime}, z, \boldsymbol{\tau}^{\prime}\right) / \Pi\left(\mathbf{1}, \boldsymbol{p}^{\prime}, z, \boldsymbol{\tau}^{\mathbf{0}}\right) .
\end{aligned}
$$

7. The Törnqvist-Theil index captures technical change as

$$
\text { Rate of Factor Productivity Change (RFPC) } \equiv \frac{1}{2}\left(k^{\circ}+k^{\prime}\right) d \ln y \text {, }
$$

where $\boldsymbol{k}^{0}$ is a vector of initial netput shares in profit $k_{i}=p_{i} y_{i} / \boldsymbol{\Pi}, \boldsymbol{k}^{\prime}$ is a vector of subsequent netput shares, and dlny is the vector of changes in the logarithms of $\boldsymbol{y}$. In the two-good case illustrated in Figure 1, RFPC (in levels) corresponds to area gcab, between $\mathrm{TC}^{0}$ and $\mathrm{TC}^{\prime}$. Diewert (1976) has previously confirmed that the rate of technical change measured by the Törnqvist-Theil index is bounded by those implied by $\mathrm{TC}^{0}$ and $\mathrm{TC}^{\prime}$. Also, he shows that this index provides an approximation to productivity change that is exact for certain production functions, exposing the link between index measurement and econometric estimation.

8. The measure of technical change (3), $\mathrm{TC}^{0}$, implies a move from $A$ to $F$ (at constant prices $p^{0}$ ), or $\left(y_{07}-y_{03}\right)$ on the vertical axis of the lower panel. The move from $A$ to $F$ can be decomposed into a move from $A$ to $C$ plus a move from $C$ to $F$. Using Allais concepts, equilibriums $A$ and $C$ are isohedoneous while $C$ and $F$ are on the same output isoquant. If one draws a budget line of slope $p^{0}$ through hypothetical equilibrium $C$ and labels the intercept with the vertical axis $y_{08}$ (not shown in the graph) then for this two-goods economy:

$$
\begin{aligned}
\mathrm{TC}^{0}= & \left(y_{07}-y_{08}\right)+\left(y_{08}-y_{03}\right)=\left(y_{07}-y_{03}\right) \text { or } \\
\mathrm{TC}^{0}= & \Pi\left(1, p^{0}, \tau^{\prime}\right)-\Pi\left(1, p^{0}, \tau^{0}\right)=\Pi\left(1, p^{0}, \tau^{\prime}\right)-E\left(1, p^{0}, u^{0}\right)=\left[\Pi\left(1, p^{0}, \tau^{\prime}\right)\right. \\
& \left.-p^{0} y^{r}\right]+\left[p^{0} y^{r}-E\left(1, p^{0}, u^{0}\right)\right]=\left[\Pi\left(1, p^{0}, \tau^{\prime}\right)-\Pi\left(1, p^{1}, \tau^{\prime}\right)\right] \\
& +\left[E\left(1, p^{h}, u^{0}\right)-E\left(1, p^{0}, u^{0}\right)\right]-y^{r}\left(p^{h}-p^{l}\right) \\
= & \int_{p^{l}}^{p^{0}} \nabla_{p} \Pi\left(1, p^{0}, \tau^{\prime}\right) d p+\int_{p^{0}}^{p^{h}} \nabla_{p} E\left(1, p^{0}, u^{0}\right) d p-y^{r}\left(p^{h}-p^{l}\right)
\end{aligned}
$$

making the connection between the lower panel and the upper panel of Figure 1 obvious.

9. There have been a number of studies that modify this definition of the rate of technical change to include adjustments for characteristics of the production structure typically ignored in productivity growth computations, but that affect the valuation of inputs and outputs. These include situations where there are discrepancies between market prices and marginal productivities. The adjustments are based on finding producers' shadow values for all inputs and outputs to substitute for market prices in profits (or costs). Distortions considered have been those from imperfect competition (see for example the studies in Cowing and Stevenson, 1981, and more recently Basu and Fernald 2001), from underutilization of capacity (see Berndt and Fuss, 1986, and other papers in that special issue of the Journal of Econometrics), from economies of scale (Ohta 1975), from pollution abatement regulations (Denison 1979; Norsworthy, et al., 1979; Crandall 1981; Christiansen and Haveman, 1981; Pittman, 1983; Färe, et al., 1989; Conrad and Morrison, 1989), or from the existence of a common-property renewable resource (Capalbo, 1986). These producer-oriented studies focus on measuring technical change as a shift in the technology set.

10. The study of welfare losses, changes in surplus, deadweight loss "triangles", or waste due to inefficient systems of taxation, or excess burden as it is referred to in the public finance literature, has a long history in economics and continues as an active area of research. The existing literature is too 
voluminous for us to summarize here but excellent surveys are found in Curry et al. (1971), Allais (1973, 1977), Auerbach (1985), Slesnick (1998), and Hines (1999).

11. Hicks' compensating variation, $\mathrm{CV}$, is the maximum amount of money that could be taken away at state B and still permit the consumer to achieve the utility level of state A. In Figure 1, CV corresponds to $y_{05}-y_{02}$ in the lower panel and to area $c d b g$ in the upper panel.

12. Moreover, the expenditure function $E(1, \boldsymbol{p}, u)$ is linearly homogeneous and concave in $(1, \boldsymbol{p})$. If $E(1, \boldsymbol{p}, u)$ is twice continuously differentiable in $\boldsymbol{p}$ then these properties imply that $\nabla_{p p}^{2} E(l, \boldsymbol{p}, u)$ is a negative semi-definite matrix such that $\boldsymbol{p}^{T} \nabla_{p \boldsymbol{p}}^{2} E \boldsymbol{p}+2 \nabla_{p^{0}}^{2} E \boldsymbol{p}+\nabla_{00}^{2} E$. Since we assume that the expenditure function is increasing in utility, we may normalize this function such that at the initial equilibrium, $\partial E(1, \boldsymbol{p}, u) / \partial u=1$.

13. $\mathrm{CV}$ is defined as

$$
\text { Compensating Variation }(\mathrm{CV}) \equiv E\left(1, \boldsymbol{p}^{\prime}, u^{\prime}\right)-E\left(1, \boldsymbol{p}^{\prime}, u^{0}\right) \text {. }
$$

In Figure $1, \mathrm{CV}$ corresponds to the distance $y_{05}-y_{02}$ and area $c d b g$. The overlap between the Hicksian variations and index number theory has been noticed since the beginning (Hicks, 1942) The Variations evaluate the change in utility as a monetary measure of a difference in utility while the Konüs' (1939) quantity index, due to Allen (1949) as a reviewer to this paper noted, represents it as a ratio

$$
\begin{aligned}
& Q_{k}^{0}\left(\boldsymbol{p}^{0}, u^{\prime}, u^{0}\right) \equiv E\left(1, \boldsymbol{p}^{0}, u^{\prime}\right) / E\left(1, \boldsymbol{p}^{0}, u^{0}\right), \\
& Q_{k}^{\prime}\left(\boldsymbol{p}^{\prime}, u^{\prime}, u^{0}\right) \equiv E\left(1, \boldsymbol{p}^{\prime}, u^{\prime}\right) / E\left(1, \boldsymbol{p}^{\prime}, u^{0}\right) .
\end{aligned}
$$

These can be estimated using econometric methods but proponents of this method have typically followed a different empirical strategy. The index number approach avoids functional form assumptions on preferences but has more stringent data requirements (see Diewert, 1990a). It evaluates relative levels of welfare using Samuelson's (1948) principle of revealed preferences. In general, using either Hicksian variations or index numbers it is possible to create interval estimates of the change in welfare in either differences or ratio form. Diewert's (1992) exact and superlative welfare change indicators are averages of $\mathrm{EV}$ and $\mathrm{CV}$ which are exact for certain second order approximations to the expenditure function.

14. For the numeraire

$$
\mathrm{AS}=\nabla_{p_{0}} \Pi\left(1, \boldsymbol{p}, \tau^{\prime}\right)-\nabla_{p_{0}} E\left(1, \boldsymbol{p}, u^{0}\right) .
$$

15. An alternative measure using the ex-post utility level is defined as

$$
\begin{gathered}
\mathrm{AS}^{\prime}=\Pi\left(1, \boldsymbol{p}, \tau^{0}\right)-E\left(1, \boldsymbol{p}, u^{\prime}\right) ; \\
\nabla_{p} E\left(1, \boldsymbol{p}, u^{\prime}\right)=\nabla_{p} \Pi\left(1, \boldsymbol{p}, \tau^{0}\right),
\end{gathered}
$$

and for the numeraire

$$
\mathrm{AS}^{\prime}=\nabla_{p_{0}} \Pi\left(1, \boldsymbol{p}, \tau^{0}\right)+\nabla_{p_{0}} E\left(1, \boldsymbol{p}, u^{\prime}\right)
$$

In the special case of homothetic preferences and unbiased technical change (radial expansion of both, $P F F$ and indifference curve) AS and AS' converge because there is no income effect.

16. The area equivalent to $\mathrm{AS}^{\prime}$ is triangle $l k b$. In the case of no income effect, $\mathrm{AS}$ and $\mathrm{AS}^{\prime}$ are measured by the single triangle that results when the two triangles mentioned above merge due to the absence of a shift in the MRS

17. The corresponding changes in equilibrium quantifies of goods demanded and supplied are

$$
\frac{\mathbf{d} \mathbf{n} \mathbf{y}}{d \tau}=\left[\boldsymbol{\Sigma}(\boldsymbol{H}-\boldsymbol{\Sigma})^{-1}+\boldsymbol{I}\right](\iota \boldsymbol{\delta}+\boldsymbol{\beta}),
$$

where $\boldsymbol{I}$ is the identity matrix and the other terms have been defined in the text

18. This is the second order Taylor approximation:

$$
\begin{aligned}
\mathrm{AS} & \equiv \pi\left(1, \boldsymbol{p}, \tau^{\prime}\right)-E\left(1, \boldsymbol{p}, u^{0}\right) \\
& \approx \pi\left(1, \boldsymbol{p}^{0}, \tau^{0}\right)-E\left(1, \boldsymbol{p}^{0}, u^{0}\right)+\nabla_{\boldsymbol{p}} \pi^{0} \hat{\boldsymbol{p}} \mathbf{d} \ln \mathbf{p}+\nabla_{\tau} \pi^{0} d \tau-\nabla_{p} E \hat{\boldsymbol{p}} \mathbf{d l n} \mathbf{p} \\
& +\frac{1}{2} \mathbf{d} \ln \mathbf{p}^{T}\left[\hat{\boldsymbol{p}} \nabla_{p p}^{2} \pi^{0} \hat{\boldsymbol{p}}\right] \mathbf{d} \ln \mathbf{p}-\frac{1}{2} \mathbf{d} \ln \mathbf{p}^{T}\left[\hat{\boldsymbol{p}}^{T} \nabla_{\boldsymbol{p} \boldsymbol{p}}^{2} E \hat{\boldsymbol{p}}\right] \mathbf{d} \mathbf{l n p}+\mathbf{d} \ln \mathbf{p}^{T}\left[\hat{\boldsymbol{p}} \nabla_{\boldsymbol{p} \tau}^{2} \pi^{0}\right] d \tau
\end{aligned}
$$


In the text the first two terms are not included given that they sum to zero. We note also that as we are considering a once and for all technical change, throughout the paper we assume $\nabla_{\tau \tau}^{2} \pi=0$.

19. By making the following substitutions:

$$
\begin{aligned}
& \nabla_{\tau} \Pi=\delta \Pi^{0}, \\
& \nabla_{w \tau}^{2} \Pi=\hat{y}(\iota \delta+\beta), \text { where } \hat{y} \text { is a diagonal matrix of netputs } \Pi_{w}, \\
& \nabla_{w w}^{2} E=\hat{y} \Sigma \hat{w}^{-1} \text {, where } \Sigma \text { is the netput supply elasticity matrix, } \\
& \nabla_{\mathrm{pp}}^{2} \Pi=\hat{y} \mathrm{H} \hat{p}^{-1} \text {, where } \mathrm{H} \text { is the netput demand elasticity matrix, and } \\
& \hat{k}=\hat{y} \hat{w} \text {, a diagonal matrix of netput shares, } \\
& \text { equation (15) may be expressed as (16). }
\end{aligned}
$$

20. From here on we will refer to potential welfare changes with the phrase "welfare changes." A similar expression can be derived for the ex-post Allais measure, $\mathrm{AS}^{\prime}$, defined in footnote 13.

21. Parham et al. (2000) recognizes the need for a number of adjustments to economy wide total factor productivity growth (with perfect competition and constant returns to scale) to obtain growth in real income, a crude welfare change indicator. These are: changes in the capital labor ratio, the growth of the population of working age, the growth in labor force participation, changes in terms of trade and changes in the unemployment rate. The factors we focus on are not included in this list. Basu and Fernald (2002) also identify this divergence but their analysis is not based on microfoundations, as noted by Morrison Paul (2001).

22. Many of these factors are mentioned in Diewert $(1983,2001)$. Diewert (1983) uses an Allais welfare measure to capture waste in the production sector of the economy due to "imperfections." Diewert's paper does not include technical change.

23. Consequently the hypotenuses of the welfare triangles are straight lines rather than curves. The second order Taylor expansion is

$$
\begin{aligned}
\mathrm{AS} \cong & \nabla_{\tau} \Pi+\rho \hat{w} \nabla_{w \tau}^{2} \Pi+\left[\rho \hat{w} \nabla_{w w}^{2} \Pi+\nabla_{\tau w}^{2} \Pi(I+\hat{\rho})\right] w \prime \\
& +\frac{1}{2} w^{\prime T}\left[\nabla_{w w}^{2} \Pi+2 \hat{\rho} \nabla_{w w}^{2} \Pi-(I+\hat{\rho}) \nabla_{p p}^{2} E(I+\hat{\rho})\right] w^{\prime} \\
= & \nabla_{\tau} \Pi+\rho \hat{w}\left[\mathrm{I}+\nabla_{w w}^{2} \Pi\left(\nabla_{p p}^{2} E(I+\hat{\rho})-\nabla_{w w}^{2} \Pi\right)^{-1}\right] \nabla_{w \tau} \Pi \\
& +\frac{1}{2} \nabla_{\tau p}^{2} \Pi\left\{(I+\hat{\rho})+\left(\nabla_{p p}^{2} E(I+\hat{\rho})\right.\right. \\
& \left.\left.-\nabla_{w w}^{2} \Pi\right)^{-1 T} \hat{\rho} \nabla_{w w}^{2} \Pi\right\}\left(\nabla_{p p}^{2} E(I+\hat{\rho})-\nabla_{w w}^{2} \Pi\right)^{-1} \nabla_{p \tau}^{2} \Pi .
\end{aligned}
$$

To obtain equation (18), in addition to the substitutions in endnote (19) we add:

$$
\begin{aligned}
\Pi^{0} / E^{0}= & 1 /(1+k \rho) \text { allowing us to express }(18) \text { also as } \\
\mathrm{AS} / E^{0}= & \delta+\rho \hat{k}\left[I+\Sigma(\mathrm{H}-\Sigma)^{-1}\right](\iota \delta+\beta)+\frac{1}{2}(\iota \delta+\beta)^{T}[(I+\hat{\rho}) \hat{k} \\
& \left.+(\mathrm{H}-\Sigma)^{-1 \mathrm{~T}} \hat{k} \hat{\rho} \Sigma\right](\mathrm{H}-\Sigma)^{-1}(\iota \delta+\beta) .
\end{aligned}
$$

24. Cowings and Stevenson (1981), Hall (1990), Hulten (2000), Basu and Fernald (2001).

25. The first equation can be equivalently written

$$
\text { a. } \quad E(1, \boldsymbol{p}, u)+A S=\Pi(1, w, \tau)+(\boldsymbol{p}-\boldsymbol{w}) \nabla_{w} \Pi .
$$

26. As stated before there will be no price effect when technological change biases for all commodities except the numeraire are equal to the negative of the rate of technical change $\left(-\delta=\beta_{i}\right)$, or when all prices are exogenous, i.e. when the diagonal elements of the matrices $\boldsymbol{\Sigma}$ or $\boldsymbol{H}$ approach infinity.

27. It is interesting to contrast this conclusion with the one obtained when EV is used to measure the welfare gains from technological change. $\mathrm{EV} / E=\delta$ when preferences are homothetic and technical change is unbiased, regardless of policy distortions, and $\mathrm{EV} / E=A S / E$ only when there are no price effects (Perrin and Fulginiti, 2001).

28. Demand elasticities for the numeraire, $A$, and $B$ were set at $-0.17,-0.5$ and -0.5 , while supply elasticities were set at $0.67,1.0$ and 1.0 . 


\section{References}

Auerbach, A. J. (1985). "The Theory of Excess Burden and Optimal Taxation” In M. Feldstein, (ed), Handbook of Public Economics, Vol. 1, New York and Oxford: North-Holland, pp. 61-127.

Allais, M. (1973)."La Theorie Generale des Surplus et l'Apport Fondamental de Vilfredo Pareto," Revue d'Economic Politique 6, 1044-1097.

Allais, M. (1977). "Theories of General Equilibrium and Maximum Efficiency," In G. Schwodiauer, (ed.), Equilibrium and Disequilibrium Theory. Hingham, MA: D. Reidel.

Allen, R. D. G. (1949). "The Economic Theory of Index Numbers," Economica, NS 16, 197-203.

Basu, S. and J. Fernald. (2001). "Why is Productivity Procyclical? Why Do We Care?" In C. R. Hulten, E. R. Dean and M. J. Harper (eds.), New Developments in Productivity Analysis, Studies in Income and Wealth, Vol. 63, NBER, Chicago: University of Chicago Press.

Basu, S. and J. Fernald. (2002). "Aggregate Productivity and Aggregate Technology," European Economic Review 46, 963-991.

Berndt, E. R. and M. Fuss. (1986). "Productivity Measurement Using Capital Asset Valuation to Adjust for Variations in Utilization." Journal of Econometrics 33, 7-30.

Binswanger, H. (1974). "The Measurement of Technical Change Biases with Many Factors of Production." American Economic Review 64, 964-976.

Capalbo, S. (1986). "Temporary Equilibrium Production Models For a Common-Property RenewableResource Sector.” Journal of Econometrics 33, 263-284.

Christiansen, G. and R. Haveman. (1981). "The Contribution of Environmental Regulations to the Slowdown in Productivity Growth." Journal of Environmental Economics and Management, 381-390.

Conrad, K. and C. Morrison. (1989). "The Impact of Pollution Abatement Investment on Productivity Change: An Empirical Comparison of the U.S., Germany, and Canada." Southern Economic Journal 55, 684-698.

Cowing, T. G. and R. E. Stevenson. (1981). Productivity Measurement in Regulated Industries. New York: Academic Press.

Crandall, R. W. (1981). "Pollution Controls and Productivity Growth in Basic Industries." In T. G. Cowing and R. E. Stevenson, (eds.), Productivity Measurement in Regulated Industries. New York: Academic Press.

Curry, J. M., J. A. Murphy and A. Schmitz. (1971). "The Concept of Economic Surplus and its Use in Economic Analysis". Economic Jl, 81, 741-799.

Debreu, G. (1951). "The Coefficient of Resource Utilization." Econometrica 19, 273-292.

Denison, E. (1979). Accounting for Slower Economic Growth: The United States in the 1970s. Washington, D.C.: The Brookings Institation.

Diewert, W. E. (1976). "Exact and Superlative Index Numbers", Journal of Econometrics 4, 115-145.

Diewert, W. E. (1980). "Capital and the Theory of Productivity Measurement." American Economic Review 70(2), 260-267.

Diewert, W. E. (1981). "The Measurement of Deadweight Loss Revisited." Econometrica 49, 1225-1244.

Diewert, W. E. (1983) "The Measurement of Waste Within the Production Sector of an Open Economy." Scandinavian Journal of Economics 85, 159-179.

Diewert, W. E. (1990). "The Theory of the Cost-of-Living Index and the Measurement of Welfare Change”. In W. E. Diewert, (ed.), Price Level Measurement. Amsterdam: North Holland.

Diewert, W. E. (1992a). "Exact and Superlative Welfare Change Indicators." Eonomic Inquiry 30, 565582.

Diewert, W. E. (1992b). "Fisher Ideal Output, Input, and Productivity Indexes Revisited" Journal of Productivity Analysis 3, 211-248.

Diewert, W. E. (2001). "Which (Old) Ideas On Productivity Measurement are Ready to Use?" In C. R. Hulten, E. R. Dean and M. J. Harper (eds.), New Developments in Productivity Analysis. Studies in Income and Wealth, Vol. 63, NBER. Chicago: University of Chicago Press.

Diewert, W. E. and C. J. Morrison. (1986). "Adjusted Output and Productivity Indexes for Changes in the Terms of Trade." Economic Journal 96, 659-679. 
Diewert, W. E. and A. O. Nakamura. (2003). "Index Number Concepts, Measures and Decomposition of Productivity Growth." Journal of Productivity Analysis 19, 127-159.

Dixit, A. and V. Norman. (1979). Theory of International Trade. Cambridge: Cambridge University Press.

Färe, R., S. Grosskopf, C. A. K. Lovell and C. Pasurka. (1989). "Multilateral Productivity Comparisons When Some Outputs are Undesirable: A Nonparometric Approach." The Review of Economics and Statistics 71, 90-98.

Griliches, Z. (1957) "Hybrid Corn: An Exploration in the Economics of Technological Change." Econometrica $25,501-523$.

Griliches, Z. (1994). "The Discovery of the Residual: A Historical Note". Journal of Economy. Literature 34, 1324-1330.

Hall, R. E., (1990). "Invariance Properties of Solow's Productivity Residual.” In Peter Diamond (ed.), Growth, Productivity, Employment. Cambridge: MIT Press.

Hicks, J. R. (1942). "Consumers' Surplus and Index Numbers." Review of Economic Studies 9, 126-137.

Hicks, J. R., (1945-1946). "The Generalized Theory of Consumer's Surplus." Review of Economic Studies $13,68-74$.

Hines, J. R (1999). “Three Sides or Harberger Triangles.” Journal of Economic Perspectives 13(2), 167188.

Hulten, Charles R. (2000). "Total Factor Productivity: A Short Biography." NBER Working Paper 7471, Cambridge, MA, January 2000.

Jorgenson, D. and Z. Griliches (1967). The Explanation of Productivity Change", Rev. Econ. Stud. 34, 249-283.

Kohli, U. (1991). Technology, Duality, and Foreign Trade: The GNP Function Approach to Modeling Imports and Exports. London: Harvester Wheatsheaf.

Konüs, A. A. (1939). "The Problem of the True Index of the Cost-of-Living." Econometrica 7, 10-29.

Morrison Paul, C. (1999). Cost Structure and the Measurement of Economic Performance. MA: Kluwer.

Morrison Paul, C. (2001). Comment on "Why is Productivity Procyclical? Why Do We Care?" In C. R.

Hulten, E. R. Dean and M. J. Harper (eds.), New Developments in Productivity Analysis, Studies in Income and Wealth, Vol. 63, NBER. Chicago: University of Chicago Press.

Norsworthy, J., M. Harper and K. Kunze. (1979). "The Slowdown in Productivity Growth: Analysis of Some Contributing Factors." Brookings Papers in Economic Activity 2, 387-421.

Ohta, M. (1975). "A Note on the Duality Between Production and Cost Functions: Rate of Returns to Scale and Rate of Technical Progress" Economic Studies Quarterly 25, 63-65.

Parham, D., P. Barnes, P. Roberts and S. Kennett. (2000). Distribution of the Economic Gains of the 1990s. Productivity Commission Staff Research Paper, Canberra: AusInfo. Website: http://www.pc.gov.au/research/stafres/doteg/doteg.pdf

Pittman, R. W. (1983). "Multilateral Productivity Comparisons with Undesirable Output." The Economic Journal 93, 883-891.

Perrin, R. and L. Fulginiti (2001). "Technological Change and Welfare in an Open Economy with Distortions" American Journal of Agricultural Economics 83, 455-464.

Samuelson, P., (1948). Foundations of Economic Analysis. Cambridge: Harvard. U. Press.

Slesnick, D. T. (1998). "Empirical Approaches to the Measurerment of Welfare." Journal of Economic Literature 36, 2108-2165.

Solow, R. M. (1957). "Technical Change and the Aggregate Production Function." Review of Economics and Statistics 39, 321-320.

Tinbergen, J. (1942). "Zur Theoie der Langfirstigen Wirtschaftsentwicklung." Weltwirts. Archiv. 1, 511549, Amseterdam, North Holland, 1942; reprinted in English translation in Jan Tinbergen: Selected Papers, North Holland, 1959.

Woodland, A. D. (1982). International Trade and Resource Allocation. Amsterdam: North-Holland. 